$\ll$ Research Note $\gg$

\title{
Do the Avian Cells Behave Like Mammalian?
}

\author{
Diana Wesselinova \\ Department of Immunology Institute of Experimental Pathology and Parasitology, BAS, Sofia \\ 1113, BULGARIA, “Acad. G. Bonchev”, B1. 25
}

\begin{abstract}
Using the fluorescent polarization $(\mathrm{P})$ it is shown that the avian cell membranes change their fluidity in some circumstances like the mammalian cells. The cells from a liver tumor (myelocytoblastoma) were compared to normal leukocytes, macrophages and bone-marrow cells in turkeys. It turned out that the cancer cells really showed increased fluidity. The bone-marrow cells could not adsorb the fluorescent probe and the viscosity remained undistinguished.
\end{abstract}

Key words : membrane fluidity, avian cancer cells, fluorescence

\section{Introduction}

The cell membrane fluidity is a very useful property especially by examining the malignant transformation but still not widely used in the anticancer therapy. In current time there are some interesting data of Pacilio et al. (1998) who basing on changes in the membrane fluidity of various human cell lines and the use of different drugs tried to accomplish certain therapy. Iwagaki et al. (1996), Stalc et al. (1992) and Salyer et al. (1990) have mentioned that $\chi$ IFN increases and the tumor necrosis factor (TNF) decreases the fluidity of the examined tumor cells. The membrane fluidity changes very early in the cell differentiation to tumor stage and therefore it can be used as a sure and hopeful criterion for determination and diagnosis of cancer. It is well known that significant changes in the cell membrane fluidity have been observed in human malignant cells as compared to their normal analogues (Daefler et al., 1987). Do the avian cells change in the same manner? The aim of this study was to examine this.

\section{Material and Methods}

Animals : 2-3 weeks old turkeys were infected i.v. with the virus strain Mc 31 (myelocytomatosis virus) and killed after they developed tumors in the liver.

Procedure: The tumor cell membrane fluidity (myelocytoblasts) that I used was not examined and I was curious whether avian tumor cells do possess similar properties as the mammalian analogues. The microviscosity $(\eta)$ of some investigated physiological or synthetic membranes can be calculated by measuring their fluorescent polarisation (P) after incubation with the non-lipid apolar fluoroprobe 1,6-diphenil-1, 3, 5hexatriene (DPH). The method of Daefler et al. (1987) has been used with slight modifications. Shortly it has been done as follows : DPH ("Sigma") $2.10^{-3} \mathrm{M}$ in tetrahydrophuran ( "Sigma")was diluted 1000 times in $0.15 \mathrm{M} \mathrm{NaCl}$ and $10 \mathrm{mM}$ Tris (pH 7.4) and gently stirred to opalescence. In this solution $10^{6} / \mathrm{m} l$ of the examined cells 
were incubated and the time (in min.) was counted for a maximal adsorbtion of the probe. The labelling was repeated under optimal incubation conditions; the cells were washed and the fluorescent polarization (P) was measured by simultaneous determinations of the fluorescent activities (I) by horizontal (parallel) (h) and vertical (v) to the direction of the polarized exiting beam. The fluorescent polarization (P) was calculated according to the equation (Daefler et al., 1987) :

$$
\mathbf{P}=\frac{\mathbf{I}_{\mathrm{vv}}-\mathbf{I}_{\mathrm{vh}}}{\mathbf{I}_{\mathrm{vv}}+\mathbf{I}_{\mathrm{vh}}}
$$

The exitation wave-lenght $\left(E_{x}\right)$ was $348 \mathrm{~nm}$ and the emmision wave-lenght $\left(E_{m}\right)$ was $426 \mathrm{~nm}$. The fluorescence was carried out with spectrofluorimeter "Nova 2" ( "Biard", UK).

\section{Results and Discussion}

The myelocytoblastoma we used (Mc 31) is a tumor with still unclear origin - its normal analogue remains undistinguished. It is only stated that the tumor cells are closy related to macrophages and bone marrow cells (haemocytoblasts). This was the reason to compare these tumor cells with macrophages, bone marrow cells and (as exeption) with leukocytes.

The received data after the fluidity measurements of the Mc 31-tumor cells and the other normal cells gave my positive reason for an early determination of the transformation phase of these (or probably of each kind) malignant cells. As Daefler et al. (1987) stated, the malignant transformation is accompanied by damages of the cell membrane and of some functions that could influence its lipid component and from there - its fluidity. They determined that the high values of the membrane fluorescent polarization (P) indicated low lipid viscosity and vice versa.In human chronic lymphocytic leukemia (CLL) the same authors gave data about the fluidity of leukemia lymphocytes and their normal counterparts (CLL-cells $-\mathrm{P} \approx 0.258$; normal lymphocytes $-\mathrm{P} \approx 0.285$ ).

The fluorescent polarization values (Table 1) of the examined cell membranes showed a lower polarization (=higher fluidity) of the Mc 31-transformed cell membranes as compared to these of the normal cells (bone-marrow cells, macrophages and

Table 1. Cell membrane polarization (fluidity) of turkey malignant cells transformed by the virus strain Mc 31 and of normal turkey cells

\begin{tabular}{lcc}
\hline \hline \multicolumn{1}{c}{ Cells } & Polarization values $(\mathrm{P})^{1}$ \\
\hline Mc 31 tumor cells (myelocy toblasts) & & \\
from liver hemocytoblastoma & 0.059 & $\mathrm{p}<0.03^{3}$ \\
Normal leukocytes & 0.066 & $\mathrm{p}<0.01$ \\
Normal macrophages ${ }^{2}$ & + & \\
Normal bone-marrow cells & 0 & \\
\hline 1'-results from 3 samples with $10^{6}$ cells each & \\
${ }^{2}$-very low fluorescence that cannot be calculated. \\
${ }^{3}$-Student's statistical analysis
\end{tabular}


normal leucocytes).

It seems that the normal macrophages difficultly adsorb the fluoroprobe DPH and the fluorescence was hardly visible ; therefore the viscosity could not be calculated. The normal bone-marrow cells did not fluoresce at all (it did not adsorb this probe) and therefore I decided to choose the normal turkey leukocytes as another control. The application of another fluoroprobe might probably afford the labelling of all the examined cells.

On Table 1 it is visible that the polarization values of the Mc 31-transformed cells were lower than those of the normal leukocytes (the variations are in the range of $10^{2}$ to $10^{3}$ but this is a common fact). It is well known that the polarization and fluidity of the cell membranes are in opposite correlation (low $\mathbf{P}=$ high fluidity). In all available data cells from human and mice have been examined what hindered the comparison of the polarization values (Shinitzky and Inbar, 1974 ; Shinitzky, 1984 ; Daefler et al., 1987) with the examined appropriate cell lines.

Krueger et al. (1987) proved in mice (treated with Moloney- or Friend-viruses) that the viruses did not induce change in the membrane fluidity of the cell clones while control cells (from healthy mice) showed an increased fluidity by the differentiation back to young cells - e.g. the erithropoietic stem cells exhibited higher cell membrane fluidity (CMF).

The P-values in our experiments indicated an increased viscosity of the tumor cell membranes. We could definitly speculate that namely this change of the cell membrane influences the contact inhibition of all (mammalian and avian) malignant transformed cells.

\section{References}

Daefler S, Krueger G, Modler M and Deliconstantinos G. Cell membrane fluidity in chronic lymphocytic leukemia (CLL) lymphocytes and its relation to membrane receptor expression. Journal of Experimental Pathology, 3(2) : 147-54. 1987.

Iwagaki H, Marutaka M, Yoshino T, Caol L, Skauma I, Takeuchi M and Tanaka N. Gammainterferon upregulates transferrin receptors and decreases membrane microviscosity in K 562 cells. Research Communication in Molecular Pathology and Pharmacology, 92(2) : 191200. 1996.

Krueger G, Stolzenburg Th and Muller C. Cell membrane lipid fluidity and receptor expression in Moloney- and Friend-virus transformed cells. "In vivo", 1 : 343-46. 1987.

Pacilio C, Florio S, Pagnini U, Crispino A, Claudio P, Pacilio G and Pagnini G. Modification of membrane fluidity and depolarization by some anthracyclines in different cell lines. Anticancer Research, 18(6 A) : 4027-34. 1998.

Salyer JL, Bohnsack JF, Knape WA, Shigeoka AO, Ashwood ER and Hill HR. Mechanisms of TNF-a alteration of PMN adhesion and migration. American Journal of Pathology, 136(4) : 831-41. 1990.

Shinitzky $M$ and Inbar M. Difference in microviscosity induced by different cholesterol levels in the surface membrane lipid layer of normal lymphocytes and malignant lymphoma cells. Journal of Molecular Biology, 85 : 603-15. 1974.

Shinitzky M. Membrane fluidity in malignancy. Adversative and recuperative. Biochemica, Biophysica Acta, 738 : 251. 1984.

Stalc A, Sentjurk M, Sersa G and Novakovic S. The influence of TNF on the membrane fluidity of tumor cells. Cancer Letters, 65(3) : 183-187. 1992. 